\title{
Adaptation and Radiation-Induced Chromosomal Instability Studied by Statistical Modeling
}

\author{
Victoria L. Korogodina*, ${ }^{* 1}$, Boris V. Florko ${ }^{1}$ and Ludmila P. Osipova ${ }^{2}$ \\ ${ }^{1}$ Joint Institute for Nuclear Research, Dubna, Russia \\ ${ }^{2}$ Institute of Cytology and Genetics of RAS, Novosibirsk, Russia
}

\begin{abstract}
It is known that irradiation stress induces late intracellular processes and adaptation. In this paper, we formulate the adaptation hypothesis. On its basis, we present statistical modeling of cellular distributions on the number of chromosomal abnormalities in root meristems of pea seeds that experienced low-dose-rate irradiation, high temperatures, and aging. The modeling shows that multiple appearances of chromosomal abnormalities can be explained as a result of primary or late processes caused by DNA damage, with or without cell selection, which can be described with geometrical or Poisson distributions, respectively. The connections between the late intercellular processes (the "bystander effects") and late intracellular regulatory processes are considered. It is shown that combinations of low-dose-rate irradiation, high temperatures, and aging lead to synergistically increasing instabilities and decreasing seed survivals. Approaches to risk estimation of chromosomal instability are investigated in plant cells and in human blood lymphocytes. Risks of instability were estimated as values of distribution parameters dependent on radiation intensity in ecology and in generations of persons who experienced radioactive fallouts from nuclear tests. We conclude that statistical model of adaptation describes intraand intercellular processes of genetic instability coupled with selection, and that the risks of these processes can be calculated as model parameters.
\end{abstract}

Keywords: Adaptation, chromosomal instability, risk of chromosomal instability, statistical modeling.

\section{INTRODUCTION}

At present, there are numerous radiation sources around the world and low irradiation doses and dose rates are common environmental factors. In the 1990s it was found that such stresses are accompanied by time-dependent genetic instabilities, which include spatial intracellular [1-4] and intercellular [5-9] spreading of DNA damage. It is important that mutations or chromosomal aberrations can accumulate in cells that experience stress conditions [10] due to the stimulation of mismatch repair [11]. It was reported that a stress-induced mutation process is coupled with selection $[12,13]$ and is observed in ecological niches where stresses dominate [14].

Multiple appearances of DNA damages can be described by a geometrical distribution of cells on the number of abnormalities [15-17]. The geometrical distribution can be modeled as a result of filtration (selection) and can be caused by adaptive processes [18].

Quantitative characteristics of adaptive processes can be estimated by statistical modeling [19]. The statistical investigations of adaptive processes in natural plantain populations growing near radiation sources were described earlier [20, 21]. Here, we present modeling of laboratory experiments on seeds of a pure pea line in which we studied the influence of aging and heat stress on the low-dose-rate irradiation effect. A connection between the adaptive processes in tissue and

*Address correspondence to this author at the Joint Institute for Nuclear Research, Dubna, Moscow region, 141980, Russia; Tel: (+7) 49621-48873; E-mail: korogod@jinr.ru cells is investigated in this paper in view of the adaptation model. The quantity characteristics of this model can provide a basis for risk estimation of genetic instability in ecology and epidemiology. Statistical modeling affords an opportunity to calculate risks of instability processes in generations.

Our aims are as follows: (i) to present an example of statistical modeling of cell distributions on the number of chromosomal abnormalities (CAs) in root meristems of pea seeds that experienced low-dose-rate irradiation, high temperatures, and aging; (ii) to analyze some regularities revealed by the modeling of adaptive processes in meristems and cells; and (iii) to provide approaches to risk estimation of instability in ecology and epidemiology.

\section{MATERIALS AND METHODS}

\section{Seeds}

Pea seeds (Pisum arvense) were the selected line Nemchinovsky-817. For this kind of seed, the reported quasithreshold radiation dose, which corresponds to the inflection of the survival curve from a shoulder to mid-lethal doses, is 10-20 Gy [22]. The seeds were collected at the end of July, 1996 and in 1997 in the field of the Agriculture Institute (Moscow region). The seeds collected in 1996 were stored in a refrigerator until April, $1997\left(\mathrm{~T}=3-4^{\circ} \mathrm{C}\right.$ and relative humidity $=13-14 \%)$. Then the first fraction of seeds was tested (stored in refrigerator $\approx 8$ months, "young"); the second group was kept in the refrigerator until April, $1998(\approx 20$ months, "old"); and the third was stored in the refrigerator for 8 months and then held outdoors until June without sunlight or precipitation but with temperature ranges during the day and the night of $30-32^{\circ} \mathrm{C}$ and $16-18^{\circ} \mathrm{C}$, respectively 
(higher than usual for the Moscow region) and relative humidity of $\approx 80 \%$ (usual for this region). The duration of heat stress was 2 months ("young seeds with heat stress").

\section{Seed Sprouting and Fixing}

Seeds of all groups were germinated on wet filter paper in petri dishes at $25^{\circ} \mathrm{C}$ until seedling roots reached $30 \pm 4$ $\mathrm{mm}$, a length corresponding to the first mitoses before which seedling growth is due only to swelling without cell division. These seedlings at the first mitosis in meristems were scored as surviving $(\mathrm{S})$. Seedlings were fixed in ethyl alcohol and acetic acid (3:1) and stained with acetoorcein. Seedlings less than $26 \mathrm{~mm}$ after 13 days were scored as non-surviving (1 S) because too few reached the first mitosis. Prolonging the germination period (up to 6 weeks) increased S by only 2$3 \%$ and the rootlets were small and brown. The methods of seed sprouting and fixing have been described [23, 24].

\section{Determination of Cells with Chromosomal Abnormalities}

Ana-telophases were scored for CAs containing chromosome bridges and acentric fragments.

\section{Irradiation of Seeds}

Pea seeds were gamma-irradiated at room temperature with $7 \mathrm{cGy}{ }^{60} \mathrm{Co}$ at $0.3,1.2$, or $19.1 \mathrm{cGy} / \mathrm{h}$. The details of irradiation have been described [24].

\section{Statistics}

In various components of the experiment with young and old peas, we used 125-174 seeds to determine S and usually analyzed $\approx 2000$ ana-telophases for each component. In the tests with "young+heat" peas we used 40 seeds and analyzed $\approx 1500$ ana-telophases for each component. The data were processed using standard statistical methods [25].

\section{Statistical Methods}

We used maximum-likelihood method for approximations. The following statistical criteria were used for the estimation of regression: (i) $\mathrm{R}_{\mathrm{adj}}$ is the determination coefficient corrected for degrees of freedom [26] (equivalent to the T-criterion known in radiobiology [27]); (ii) the AIC crite- rion (the Akaike criterion imposes limitation on minimal information distance between the model and experimental distributions) [28]; (iii) the BIC criterion (selection of the most probable models from the ensemble under the condition of a priori equal probability of any of them) [29]. The most sensitive test for our tasks is T-criterion [27], which encourages good efficiency of approximation and fines for use of large numbers of parameters.

The best hypothesis with respect to the majority of criteria was preferred. For close values of criteria, the simpler hypothesis was chosen. For a given number of experimental points, the number of model parameters is, as a rule, larger than optimal [30]; therefore, the stability of distributions was verified. The verification consisted in variation of the length of the partitioning interval upon construction of histograms. The interval length $\left(D_{\max }-D_{\min }\right) / \mathrm{M}$ was taken as the basis. Here, $\left(D_{\min }, D_{\max }\right)$ is the interval of data variation, $M=$ $\left[\log _{2}(\mathrm{~N})\right]+1$ is the number of partition intervals, and $\mathrm{N}$ is the number of data points. The verification showed the stability of the distributions.

The program FUMILI [31] was used. The search of optimal values of the model parameters was carried out in two stages. First, the initial approximation for the model parameters was found by the random search method [32] or the simulated annealing method [33]. Then the parameter values were refined using regular procedures BFGS [34] or Newton [32]. Three parameters were optimized.

\section{RESULTS}

\section{Statistical Modeling of CAs in Rootlet Meristem Cells of Unirradiated Seeds}

The geometrical distribution of cells on the number of CAs $\left(G_{c}\right)$ in the control group is shown in Table $\mathbf{1}$. It appears that correlations between the appearances of CAs originated up to "success" [35], which could be considered in this case as adapting of the genome to conditions. This suggests an adaptive process in intact cells: a DNA-damaging process coupled with selection, which checks fitness of cells. We can imagine that an additional factor influences a sensitive subpopulation of cells in the first place, and its distribution on

Table 1. Statistical Modeling of the CAs in Root Meristem Cells of Unirradiated Pea Seeds

\begin{tabular}{|c|c|c|c|c|c|c|c|c|c|c|c|}
\hline \multirow[t]{2}{*}{ Year } & \multirow{2}{*}{$\begin{array}{c}\text { CA } \\
\text { frequency }\end{array}$} & \multirow{2}{*}{$\begin{array}{c}\text { Number of } \\
\text { studied } \\
\text { ana-telophases }\end{array}$} & \multicolumn{5}{|c|}{ Number of cells with CA number } & \multicolumn{4}{|c|}{$T$ criterion $/ \chi^{2}$ criterion $(\mathrm{p}<0.05)$} \\
\hline & & & $\mathbf{0}$ & 1 & 2 & 3 & $\geq 4$ & $\mathbf{G}_{\mathbf{c}}$ & $\mathbf{G} 1_{c}+\mathbf{G} 2_{c}$ & $\mathbf{G 1}_{\mathrm{c}}+\mathbf{P}_{\mathrm{c}}$ & $\mathbf{P}_{\mathrm{c}}$ \\
\hline \multicolumn{12}{|l|}{ Young } \\
\hline 1997 & 0.17 & 3443 & 2948 & 426 & 55 & 11 & 2 & $25 /+$ & $269 /+$ & $181 /+$ & $794 /-$ \\
\hline 1997 & 0.12 & 2199 & 1931 & 238 & 25 & 5 & - & $22 /+$ & $451 /-$ & $1434 /-$ & $113 /-$ \\
\hline 1996 & 0.08 & 1097 & 1022 & 67 & 5 & 2 & 1 & $3 /+$ & $22 /+$ & $2345 /+$ & $10 /+$ \\
\hline \multicolumn{12}{|l|}{ Heat } \\
\hline 1996 & 0.11 & 4020 & 3663 & 274 & 68 & 11 & 4 & $1365 /-$ & $320 /+$ & $113 /+$ & $1614 /-$ \\
\hline \multicolumn{12}{|l|}{ Old } \\
\hline 1996 & 0.10 & 906 & 823 & 77 & 4 & 1 & 1 & $0.20 /+$ & $0.20 /+$ & $0.01 /+$ & $0.09 /+$ \\
\hline
\end{tabular}

The standard error of CA frequency is $\leq 0.01$. 
the number of CAs could be geometrical $(\mathrm{G})$ or Poisson $(\mathrm{P})$. Thus, experimental data could be compounded of $G$ and $G$ (or P) that correspond to distributions of resistant $\left(\mathrm{G} 1_{\mathrm{c}}\right)$ and sensitive $\left(\mathrm{G} 2_{c}\right.$ or $\left.P_{c}\right)$ fractions of cells. In the cases of aging and heat-stressed seeds, a sum of $G 1_{c}$ and $P_{c}$ distributions is observed (Table 1). This is expected because high temperature and aging are strong mutagenic factors $[36,37]$.

\section{Statistical Modeling of CAs in Rootlet Meristem Cells of Irradiated Seeds}

In young seeds irradiated at $0.3 \mathrm{cGy} / \mathrm{h}$, the modeling shows two G distributions (Table 2). We can assume that the second distribution $\mathrm{G} 2$ c reflects additional damaging processes in the sensitive subpopulation. At 1.2 and $19.1 \mathrm{cGy} / \mathrm{h}$, the $P_{c}$ distribution gradually displaces $G 2_{c}$ distributions. Analyses of the combined effect of radiation and high temperature reveal domination of the $\mathrm{G}$ regularities of the CAs appearance (heat stress) and addition of a $\mathrm{P}$ component (aging) (Table 2).

\section{Adaptive Processes in Meristems and Cells}

Table 3 presents general characteristics and modeling values of the appearances of both cells with CAs in meristem published earlier [24] and the CAs in cells. In the young seeds, a negligible value of the $G$ distribution $\left(G_{s}\right)$ on the number of cells with abnormalities is coupled with a negligible value of the $\mathrm{G} 2$ c distribution at $0.3 \mathrm{cG} / \mathrm{h}$ that is accompanied by decreasing frequencies of $\mathrm{R} 1, \mathrm{R} 2$, and survival (Table 3). It is basic to think that intensive radiation-induced bystander effects in meristem lead to intensive DNA damage in its cells, which together decrease the survival of cells and seeds. P distributions of seedlings and cells are observed at 1.2 and $19.1 \mathrm{cGy} / \mathrm{h}$. At $19.1 \mathrm{cGy} / \mathrm{h}$, the parameters $\mathrm{mP}_{\mathrm{s}}$ $(0.85 \pm 0.20)$ and $\mathrm{mP}_{\mathrm{c}}(0.09 \pm 0.02)$ have low values (Table 3$)$.

In aged seeds, the negligible values of the $\mathrm{G}_{\mathrm{s}}$ and $\mathrm{G} 2_{\mathrm{c}}$ distributions are observed at $0.3 \mathrm{cGy} / \mathrm{h}$, which corresponds to increased seed survival $(p<0.05)$. This increase could be due to a stimulation of cell proliferation in old seeds irradiated at $0.3 \mathrm{cGy} / \mathrm{h}(\mathrm{p}<0.05)$ [24]. The $\mathrm{G}$ component is also revealed in the seeds irradiated at $1.2 \mathrm{cGy} / \mathrm{h}$. The $\mathrm{P}_{\mathrm{c}}$ distribution is revealed in the control and the 19.1-cGy/h groups, its sample mean being low (0.08-0.10 \pm 0.03$)$ (Table 3) [19]

In the heat-stressed seeds, the lowest values of the $\mathrm{G}_{\mathrm{s}}$ and $\mathrm{G} 2_{\mathrm{c}}$ distributions are observed at $1.2 \mathrm{cGy} / \mathrm{h}$. The $\mathrm{G} 2_{\mathrm{c}}$ distributions are revealed at 0.3 and $19.1 \mathrm{cGy} / \mathrm{h}$; seed survival is decreased at all these dose rates, especially at $1.2 \mathrm{cGy} / \mathrm{h}$. In the control group, the $\mathrm{P}$ distribution of cells on the number of DNA damages is characterized by an increased sample mean $(0.66 \pm 0.12)$. All these could mean increased late processes in all groups of seeds induced by heat stress. A comparison of the "old" and "heat" groups shows that heat stress induces late processes accompanied by selection stronger than produced by aging.

To quantitatively analyze the combined effects induced by irradiation and heat, we used a synergism coefficient suggested by Petin et al. [38]. These authors characterize the appearance of synergic lethal damages as $\mathrm{N}_{\Sigma}=\mathrm{N}_{1}+\mathrm{N}_{2}+$ $\min \left\{\mathrm{p}_{1} \mathrm{~N}_{1}+\mathrm{p}_{2} \mathrm{~N}_{2}\right\}$, where $\mathrm{N}_{1}, \mathrm{~N}_{2}$, and $\mathrm{N}_{\Sigma}$ are the numbers of lethal damages induced by the first, second, and combined

Table 2. Statistical Modeling on Pea Seeds Irradiated with 7 cGy with Low-Dose Intensity or Without Irradiation

\begin{tabular}{|c|c|c|c|c|c|c|c|c|c|c|c|}
\hline \multirow{2}{*}{$\begin{array}{l}\text { Dose } \\
\text { rate, } \\
\text { cGy/h }\end{array}$} & \multirow{2}{*}{$\begin{array}{c}\text { Number of } \\
\text { studied ana- } \\
\text { telophases }\end{array}$} & \multirow[t]{2}{*}{$\begin{array}{c}\text { CA } \\
\text { frequency }\end{array}$} & \multicolumn{5}{|c|}{$\begin{array}{c}\text { Number of cells with CA } \\
\text { number }\end{array}$} & \multicolumn{4}{|c|}{$\mathrm{T}$ criterion $/ \chi^{2}$ criterion $(\mathbf{p}<0.05)$} \\
\hline & & & $\mathbf{0}$ & 1 & 2 & 3 & $\geq 4$ & $\mathbf{G}_{\mathrm{c}}$ & $\mathbf{G 1} 1_{\mathrm{c}}+\mathbf{G} \mathbf{2}_{\mathrm{c}}$ & $\mathbf{G} 1_{\mathrm{c}}+\mathbf{P}_{\mathrm{c}}$ & $\mathbf{P}_{\mathrm{c}}$ \\
\hline \multicolumn{12}{|c|}{ Young } \\
\hline 0 & 2199 & 0.12 & 1931 & 238 & 25 & 5 & & $22 /+$ & $451 /-$ & $1434 /-$ & $113 /-$ \\
\hline 1.2 & 1843 & 0.07 & 1637 & 191 & 13 & 2 & & $249 /+$ & $1492 /-$ & $49 /+$ & $119 /+$ \\
\hline 19.1 & 1965 & 0.08 & 1788 & 162 & 10 & 5 & & $53 /+$ & $565 /+$ & $98 /+$ & $35 /+$ \\
\hline \multicolumn{12}{|c|}{ Heat } \\
\hline 0 & 4020 & 0.11 & 3663 & 274 & 68 & 11 & 4 & $1365 /-$ & $320 /+$ & $113 /+$ & $1614 /-$ \\
\hline 19.1 & 1274 & 0.18 & 1092 & 143 & 29 & 6 & 4 & $139 /+$ & $10 /+$ & $42 /+$ & $231 /-$ \\
\hline \multicolumn{12}{|c|}{ Old } \\
\hline 0 & 906 & 0.10 & 823 & 77 & 4 & 1 & 1 & $0.20 /+$ & $0.20 /+$ & $0.01 /+$ & $0.09 /+$ \\
\hline 0.3 & 2378 & 0.13 & 2109 & 236 & 27 & 5 & 1 & $0.05 /+$ & $0.01 /+$ & $0.01 /+$ & $0.50 /+$ \\
\hline 1.2 & 1977 & 0.15 & 1729 & 207 & 38 & 3 & & $0.18 /+$ & $0.12 /+$ & $0.06 /+$ & $0.90 /+$ \\
\hline 19.1 & 586 & 0.11 & 527 & 53 & 5 & 1 & & $0.04 /+$ & $0.02 /+$ & $0.01 /+$ & $0.30 /+$ \\
\hline
\end{tabular}

The standard error of CA frequency is $\leq 0.01$. 
Table 3. Seed Inviabilities (1 - S) of Both Cells with CAs (R1) in Seedling Meristems and CAs in Meristem Cells (R2), Parameters of the Distributions of Seeds on the Number of Cells with Abnormalities as well as Distributions of Cells on the Number of CAs

\begin{tabular}{|c|c|c|c|c|c|c|c|c|c|c|c|c|c|}
\hline \multirow[t]{2}{*}{$\begin{array}{l}\text { Dose } \\
\text { rate }\end{array}$} & \multirow[t]{2}{*}{$1-\mathrm{S}, \%$} & \multirow[t]{2}{*}{$\mathbf{R} 1$} & \multicolumn{4}{|c|}{$\begin{array}{l}\text { Distributions of seeds on the number } \\
\text { of cells with abnormalities }\end{array}$} & \multirow[t]{2}{*}{$\mathbf{R} 2^{* * * * *}$} & \multicolumn{6}{|c|}{$\begin{array}{l}\text { Distributions of cells on the number of } \\
\text { chromosomal abnormalities }\end{array}$} \\
\hline & & & $\mathbf{P}_{\mathrm{s}}$ & $\mathbf{m} \mathbf{P}_{\mathrm{s}}$ & $\mathbf{G}_{\mathrm{s}}$ & $\mathbf{m G}_{\mathrm{s}}$ & & $\mathbf{G} \mathbf{1}_{\mathrm{c}}$ & mG1 $_{c}$ & G2 $\mathbf{c}_{\mathrm{c}}$ & $\mathbf{m G 2} \mathbf{c}_{\mathrm{c}}$ & $\mathbf{P}_{\mathbf{c}}$ & $\mathbf{m} \mathbf{P}_{\mathbf{c}}$ \\
\hline \multicolumn{14}{|c|}{ Young } \\
\hline 0 & 8.0 & 10.7 & $0.33 \pm 0.07$ & $1.60 \pm 0.30$ & $0.34 \pm 0.07$ & $2.84 \pm 0.40$ & 0.12 & 1.00 & 0.88 & & & & \\
\hline 1.2 & 7.3 & 11.4 & $0.50 \pm 0.04$ & $1.52 \pm 0.20$ & $0.09 \pm 0.09$ & $2.57 \pm 0.60$ & 0.07 & 0.26 & 0.87 & & & 0.74 & 0.06 \\
\hline 19.1 & 5.5 & 9.1 & $0.58 \pm 0.04$ & $0.85 \pm 0.20$ & $0.08 \pm 0.09$ & $6.69 \pm 1.20$ & 0.08 & & & & & 1.00 & 0.09 \\
\hline \multicolumn{14}{|c|}{ Heat } \\
\hline 0 & 7.5 & 11.2 & $0.59 \pm 0.08$ & $1.1 \pm 0.2$ & $0.31 \pm 0.12$ & $13.3 \pm 1.0$ & 0.11 & 0.87 & 0.03 & & & 0.13 & 0.66 \\
\hline 19.1 & $50.0^{* * *}$ & $15.4^{*}$ & $0.22 \pm 0.08$ & $1.1 \pm 0.3$ & $0.28 \pm 0.07$ & $7.3 \pm 0.8$ & 0.18 & 0.85 & 0.11 & 0.15 & 0.60 & & \\
\hline \multicolumn{14}{|c|}{ Old } \\
\hline 0 & 21.6 & 13.1 & $0.45 \pm 0.00$ & $1.9 \pm 0.3$ & $0.00 \pm 0.08$ & $0.0 \pm 1.0$ & 0.10 & & & & & 0.99 & 0.10 \\
\hline 0.3 & $28.1^{*}$ & 12.5 & $0.64 \pm 0.00$ & $1.7 \pm 0.2$ & $0.00 \pm 0.10$ & $0.0 \pm 1.0$ & 0.13 & 0.98 & 0.12 & 0.01 & 0.69 & & \\
\hline 1.2 & 20.7 & $15.8^{*}$ & $0.55 \pm 0.03$ & $2.5 \pm 0.3$ & $0.06 \pm 0.09$ & $10.1 \pm 1.6$ & 0.15 & 0.74 & 0.19 & 0.26 & 0.02 & & \\
\hline 19.1 & $28.2^{*}$ & 13.1 & $0.40 \pm 0.00$ & $1.9 \pm 0.3$ & $0.00 \pm 0.08$ & $0.6 \pm 2.4$ & 0.11 & 0.12 & 0.32 & & & 0.88 & 0.08 \\
\hline
\end{tabular}

The difference from the non-irradiated control: ${ }^{*} \mathrm{p}<0.05 ;{ }^{* * *} \mathrm{p}<0.001 ;{ }^{* * * *}$ standard error $\sim 8-12 \%$; ${ }^{* * * * *}$ standard error $<0.03$. Standard errors of the parameters of cell distributions on CAs number do not exceed $20-30 \%$ (of the sample means) and $10-15 \%$ (of the relative values).

treatments; $\mathrm{p}_{1}$ and $\mathrm{p}_{2}$ are sublethal damages produced simultaneously. Then, the coefficient of synergism can be calculated as $\mathrm{K}_{\text {syn }}=\left(\mathrm{N}_{1}+\mathrm{N}_{2}+\min \left\{\mathrm{p}_{1} \mathrm{~N}_{1}+\mathrm{p}_{2} \mathrm{~N}_{2}\right\}\right) /\left(\mathrm{N}_{1}+\mathrm{N}_{2}\right)$. We calculated the synergism values using Tables $\mathbf{2}, \mathbf{3}$, and data on the numbers of cells with CAs reported earlier [19]. In the "heat" groups, both numbers of combined DNA damages

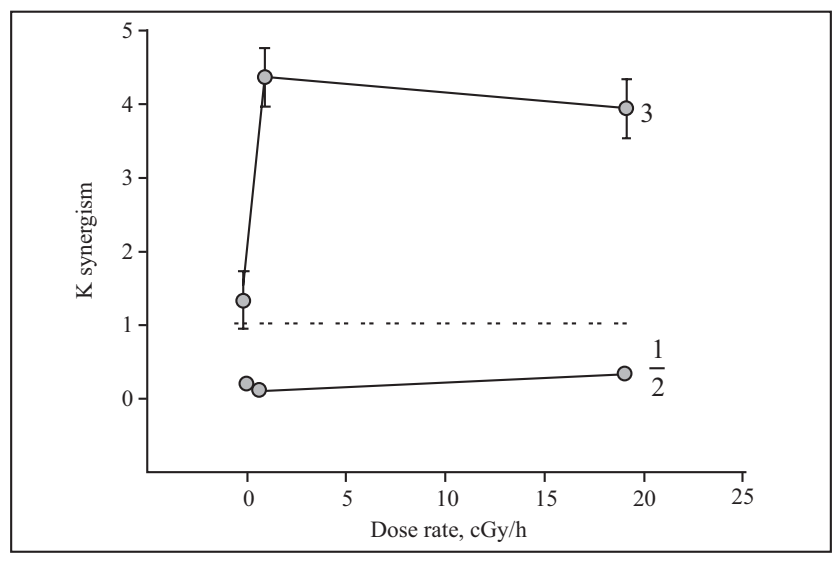

Fig. (1). Synergism coefficients of the appearances of cells with CAs (1); CAs inside cells (2); as well as of seeds' non-survival (3) for group of irradiated heat-stressed seeds. Bottom of synergism is marked by dotted line. Std. errors are shown. and combined damaged cells are decreased $\left(\mathrm{K}_{\mathrm{syn}}<1\right)$ (Fig. $\mathbf{1}$, curves 1,2 ) that can be the result of elimination of " $\mathrm{G} 2$ " "cells and " $\mathrm{G}_{\mathrm{s}}$ "- seeds (Table 3). Synergic characteristic of seeds' death $(1-S)$ increases strongly $\left(K_{\text {syn }}=4\right)$ (Fig. 1, curve 3 ). We can conclude that adaptation to combined effect of high temperature and low-dose irradiation is based on instability processes which lead to a dramatic synergistic death of cells and seeds.

\section{Adaptation Model}

The adaptive process has three components [19, 21]: primary radiation injury, which depends on the intensity of radiation $\left(\mathrm{I}_{\mathrm{rad}}\right)$; late injury, which depends on the intensity of intercellular "bystander" $\left(\mathrm{I}_{\text {byst }}\right)$ and intracellular regulatory ( $\left.\mathrm{I}_{\mathrm{reg}}\right)$ mechanisms; and selection, which depends on repair systems and environment conditions (Fig. 2).

These components can be presented by different combinations of $\mathrm{P}$ and $\mathrm{G}$ laws where $\mathrm{P}$ statistics describe the statistics of independent events $[19,21,24]$ and $G$ statistics characterize statistics after selection [16-19, 21, 24]. The primary injury and late damage follow the Poisson or binomial law [35]. In both cases, the independently occurring damages can be approximated as increasing linearly with time, that is, by the Poisson law with increased sample mean [19].

In practice, the observed $\mathrm{P}$ distribution can be the sum of $\mathrm{P}$ distributions on the numbers of primary and late damages. 


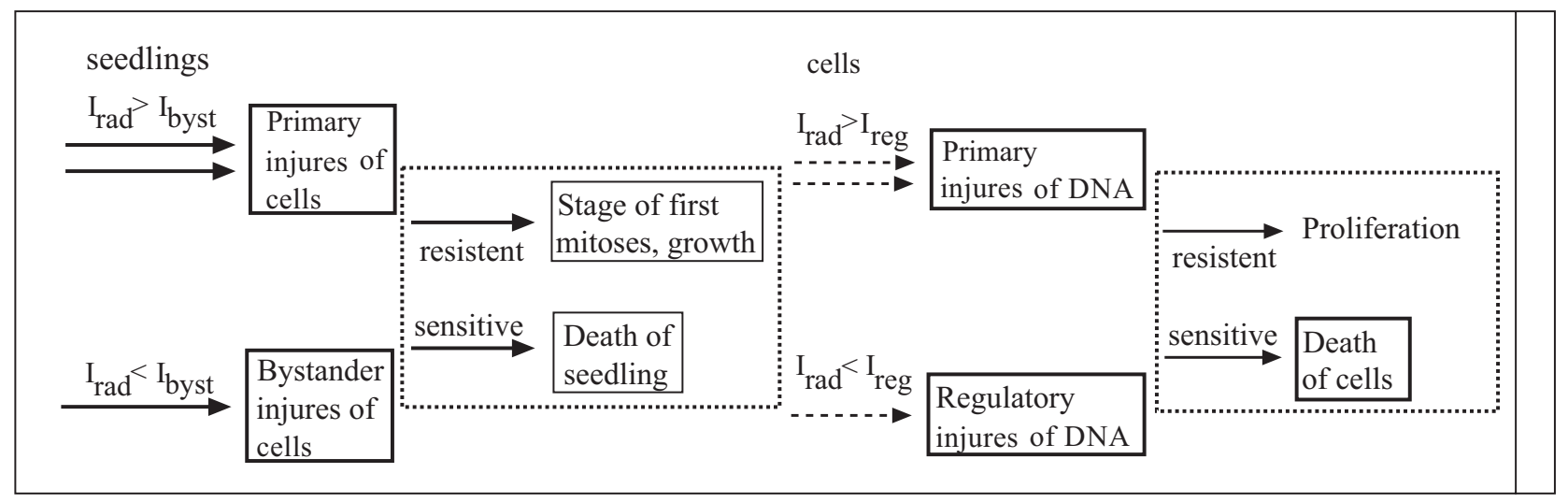

Fig. (2). Scheme of the process of seedlings' and cells' adaptation [15]. Primary injury $\left(\mathrm{I}_{\text {rad }}\right)$ induces the intercellular bystander $\left(\mathrm{I}_{\mathrm{byst}}\right)$ and intracellular regulatory $\left(I_{\text {reg }}\right)$ processes. Primary injury or late damages can be accumulated. As a result of selection, a stage of first mitoses is reached in resistant seedlings, the sensitive ones die. Intracellular processes (primary or regulatory damaging of DNA) lead to proliferation or death of cells.

The first distribution dominates if radiation intensity exceeds the regulation mechanisms of the late process $\left(I_{\text {rad }}>I_{r e g}\right)$ [21]; its sample mean is therefore low [19]. For example, a dose rate of $19.1 \mathrm{cGy} / \mathrm{h}$ (time between two hits per cell $=5$ sec) induces hits in cells in the first 2 min with averaged number of hits per cell $\approx 33$. Table 3 shows that this case corresponds to the lowest sample mean of the $\mathrm{P}$ distribution of seedlings on the number of damaged cells $(0.85 \pm 0.20)$. Irradiation at dose rates of 0.3 and $1.2 \mathrm{cGy} / \mathrm{h}$ (time between two hits $=5$ and $1.3 \mathrm{~min}$, respectively) induces bystander effects which should prevail in these cases. Complete analysis of pea data (Table 3) and especially plantain data [21] reveals the correspondence of low $\mathrm{mP}_{\mathrm{s}}$ values to low $\mathrm{mP}_{\mathrm{c}}$ values, which couple with high damage factor. Increased values of $\mathrm{mP}_{\mathrm{s}}, \mathrm{mP}_{\mathrm{c}}$ indicate late processes (for example, the control heat-stressed group, Table 3 ).

Thus, in experiments on seeds [20, 24], the distribution of seedlings on the number of cells with CAs can be approximated by $\mathrm{P}_{\mathrm{s}}+\mathrm{G}_{\mathrm{s}}$, where the $\mathrm{P}_{\mathrm{s}}$ distribution corresponds to the subpopulation of seedlings in which the bystander effect is not accompanied by the death of plants, and $\mathrm{G}_{\mathrm{s}}$ describes bystander damage accompanied by seedling selection in the more sensitive fraction $[19,21,24]^{1}$. A distribution of cells on the number of CAs can be presented as $\mathrm{G} 1_{\mathrm{c}}, \mathrm{G} 2_{\mathrm{c}}$, and $\mathrm{P}_{\mathrm{c}}$ distributions and their combination (Table 3), [21]. The $\mathrm{P}_{\mathrm{c}}$ distributions mean primary DNA damage which, together with $\mathrm{G} 2_{\mathrm{c}}$ distributions, describes the appearance of DNA damage in the sensitive fraction of cells. The appearance of an adaptive process in the resistant fraction of cells is described by the $\mathrm{G} 1_{\mathrm{c}}$ distribution.

\section{Adaptation and the Risk of Genome Instability in Eco- $\operatorname{logy}$}

We studied adaptive processes induced by fallout from the Balakovo nuclear power plant (NPP) on natural populations of plantain (Plantago major). Seeds were collected in a $30-\mathrm{km}$ zone around the NPP in years with normal high (1998) and extreme high summertime temperatures (1999) $[14,39]$. The statistical modeling was performed on the appearance of CAs in seedling meristem cells and of cells with

${ }^{1}$ The cells stimulated to proliferate are involved in the distributions.
CAs [20, 21]. Here, we present data (1999) which demonstrate a strongly synergic adaptive process which leads to a high risk of instabilities. We combined the parameters of the $\mathrm{G} 2_{\mathrm{c}}$ and $\mathrm{P}_{\mathrm{c}}$ distributions (Table 3 ) because they characterize damage to cells of the sensitive subpopulation. These parameters are correlated with the sensitive $G_{\mathrm{s}}$ subpopulation ( $p$ $<0.001$, df $=5, \mathrm{n}=7$ ), which consists of surviving and more resistant seeds of the sensitive subpopulation [21]. Thus, the $\mathrm{G}_{\mathrm{s}}$ subpopulation can be considered as a risk group of instability.

The parameters of seed distributions (Fig. 3) and cells distributions (Fig. 4) are shown as dependents on the calculated fallout dose near the NPP (Fig. 3C, D; Fig. 4C, D) and the seeds' antioxidant status (Fig. 3A, B; Fig. 4A, B) [21]. Values of surviving sensitive subpopulations of seedlings (Fig. 3D; curve 2) and cells (Fig. 4D; curve 2) decrease with fallout dose rate $(\mathrm{p}<0.1, \mathrm{df}=3, \mathrm{n}=5)$. At the border $(558$ and 1350$)$ or inside $\left(1500 \mathrm{r.u}^{2}\right)$ the $10-\mathrm{km}$ zone, approximately $70-80 \%$ of seeds died, and the value of surviving $G_{s}$ seedlings is about 2-3\%. Meristem cells of these survived adapted seedlings consist of increased number $(p<0.05)$ of late or primary DNA damages [14] (Fig. 3C, D; Fig. 4C, D; curve 2). Risks of bystander and chromosomal instability processes increase with decline of antioxidant status (Fig. 3A, B; Fig. 4A, B).

\section{Statistical Investigation of Radiation Effects Across Ge- nerations of Persons who Experienced Fallout from Nu- clear Tests}

At the beginning of the 1950s, nuclear tests were conducted in the Novaja Zemlja and Semipalatinsk sites, resulting in radioactive fallout in the Tyumen and Irkutsk regions. At present, ${ }^{137} \mathrm{Cs}$ contaminations are 153 and $118 \mathrm{~Bq} / \mathrm{kg}$ (lichen and venison, respectively) in settlements Samburg [40], and $55 \mathrm{~Bq} / \mathrm{m}^{2}$ (ground) in Maloe Goloustnoe [41]. Analyses of chromosomal breakages in blood lymphocytes of persons living in settlements Samburg (Tyumen region) or Maloe Goloustnoe (Irkutsk region) are published [42]. To investigate the consequences of irradiation across generations, we

${ }^{2}$ Evaluation of this relative dose rate can be less dependable because this population was located $\approx 100 \mathrm{~m}$ from the NPP in the shade of the smokestack. 


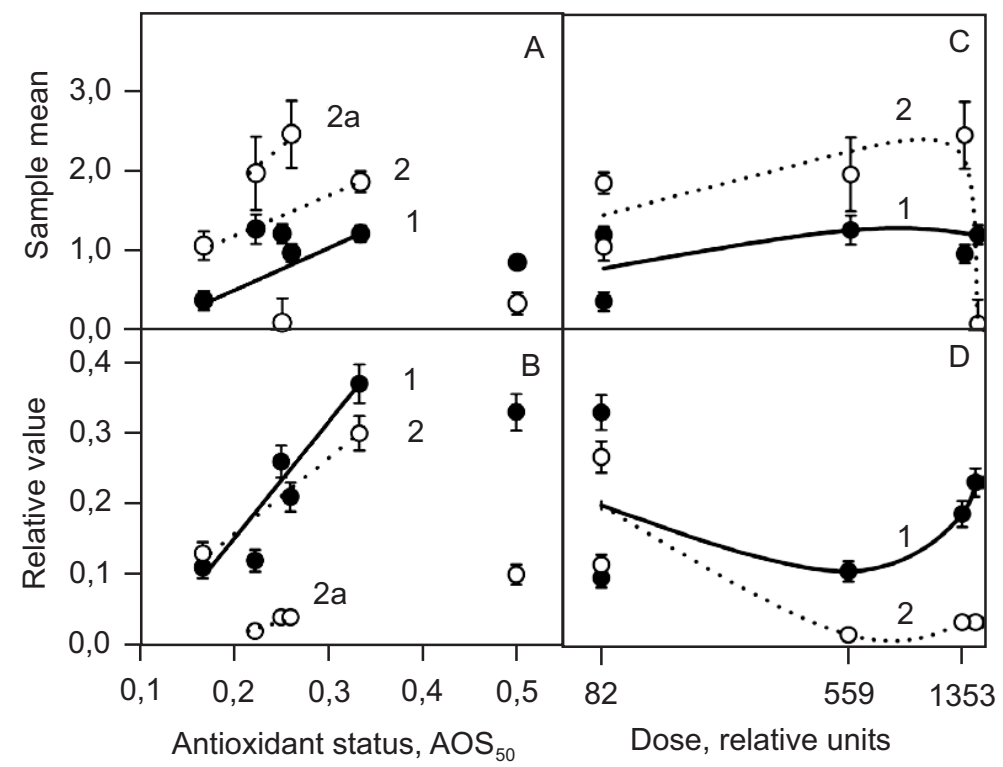

Fig. (3). The parameters of $P_{s}$ and $G_{s}$ distributions of plantain seeds on the number of cells with CAs in root meristem of seedlings [5] versus antioxidant status $(\mathbf{A}, \mathbf{B})$ and calculated relative dose $(\mathbf{C}, \mathbf{D})$. The sample mean $(\mathbf{A}, \mathbf{C})$ and value $(\mathbf{B}, \mathbf{D})$ of the $P_{\mathrm{s}}$ and $\mathrm{G}_{\mathrm{s}}$ distributions are shown (curves 1 and 2, respectively). Points with the same dose rate irradiation are connected $(\mathbf{A}, \mathbf{B})$. The regressions, $\mathbf{A}: y=-0,48+5,04 \cdot x(p$ $<0.05)(1), y=0.25+4.80 \cdot x(p<0.05)(2) ; y=-0.92+12.96 \cdot x(p<0.05)(2 a) ; \mathbf{B}: y=-0.15+1.43 \cdot x(p<0.05)(1), y=-0.04+1.02 \cdot x(p<0.05)$ (2); $y=-0.10+0.53 \cdot x(p<0.05)(2 a) ; \mathbf{C}$ : polynomial fits $(1,2) ; \mathbf{D}$ : polynomial fit $(1) ; y=100 / x^{1.4}+0.027$ (2).

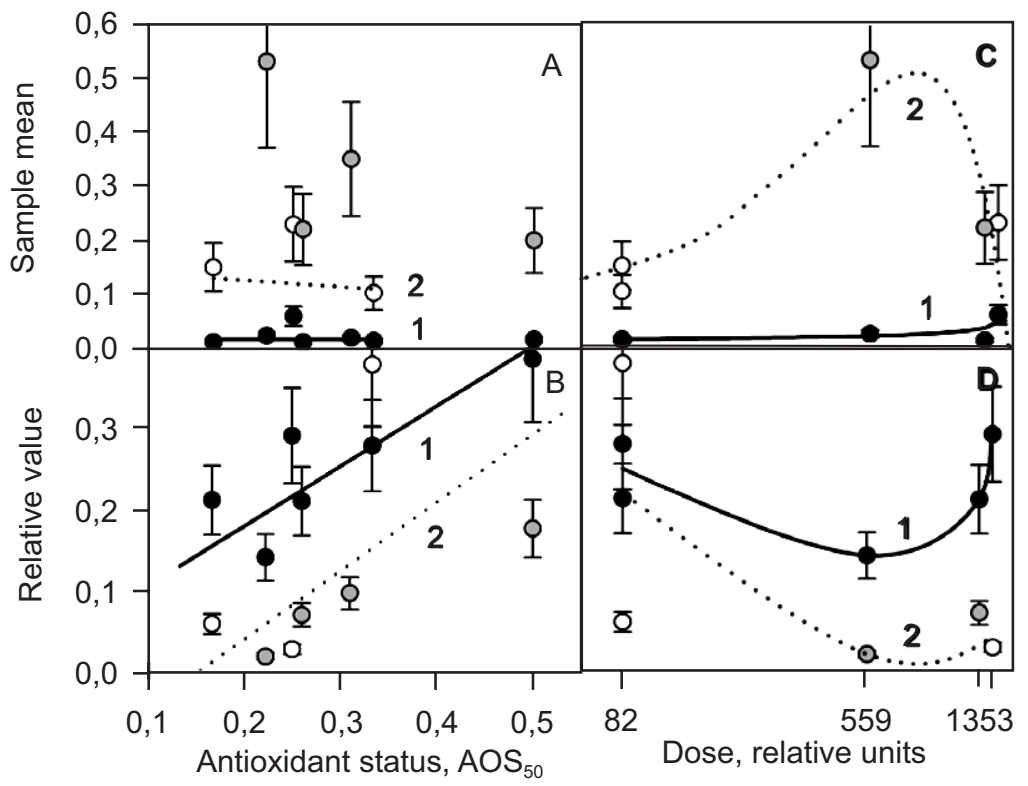

Fig. (4). The parameters of $G 1_{c}$ and $G 2_{c}, P_{c}$ distributions of plantain meristem cells on the number of CAs [15] for seeds collected around the NPP versus antioxidant status $(\mathbf{A}, \mathbf{B})$ and calculated relative dose $(\mathbf{C}, \mathbf{D})$. The sample mean $(\mathbf{A}, \mathbf{C})$ and value $(\mathbf{B}, \mathbf{D})$ of the $G 1_{c}$ and $G 2_{c}, \mathrm{P}_{c}$ distributions are shown (curves 1 and 2, respectively). Points with the same dose rate irradiation are connected (A, 1, 2). The regressions, B: $\mathrm{y}=0.73 \cdot \mathrm{x}+0,02(\mathrm{p}<0.05)(1), \mathrm{y}=0.77 \cdot \mathrm{x}-0,12(\mathrm{p}<0.05)(2) ; C$ : polynomial fits $(1,2) ; \mathrm{D}$ : polynomial fit $(1) ; \mathrm{y}=100 / \mathrm{x}^{1.4}+0.027(2)$.

analyzed distributions of individuals on the occurrence frequency of lymphocytes with CAs in blood samples of persons living in these settlements and of the control group of the city Novosibirsk inhabitants. The samples were divided into groups corresponding to individuals who were irradiated by fallout and their children, grandchildren, and greatgrandchildren. Distributions of individuals on the frequency of CAs in blood lymphocytes and approximations of these distributions are presented in Fig. (5).
The types of distributions for samples from persons living in the Tyumen and Irkutsk regions are $P, G$, and $P+G$. Analysis of distributions for the parental generation on the frequency of lymphocytes with CAs reveals a geometrical component, whereas those for grandchildren (Irkusk region) and great-grandchildren (Irkutsk and Tyumen regions) follow a Poisson distribution. A tendency is observed towards decreased sample means of the $\mathrm{P}$ distribution across generations, but it remains higher $(3.1 \div 4.2$, $\mathrm{p}<0.05)$ than the con- 


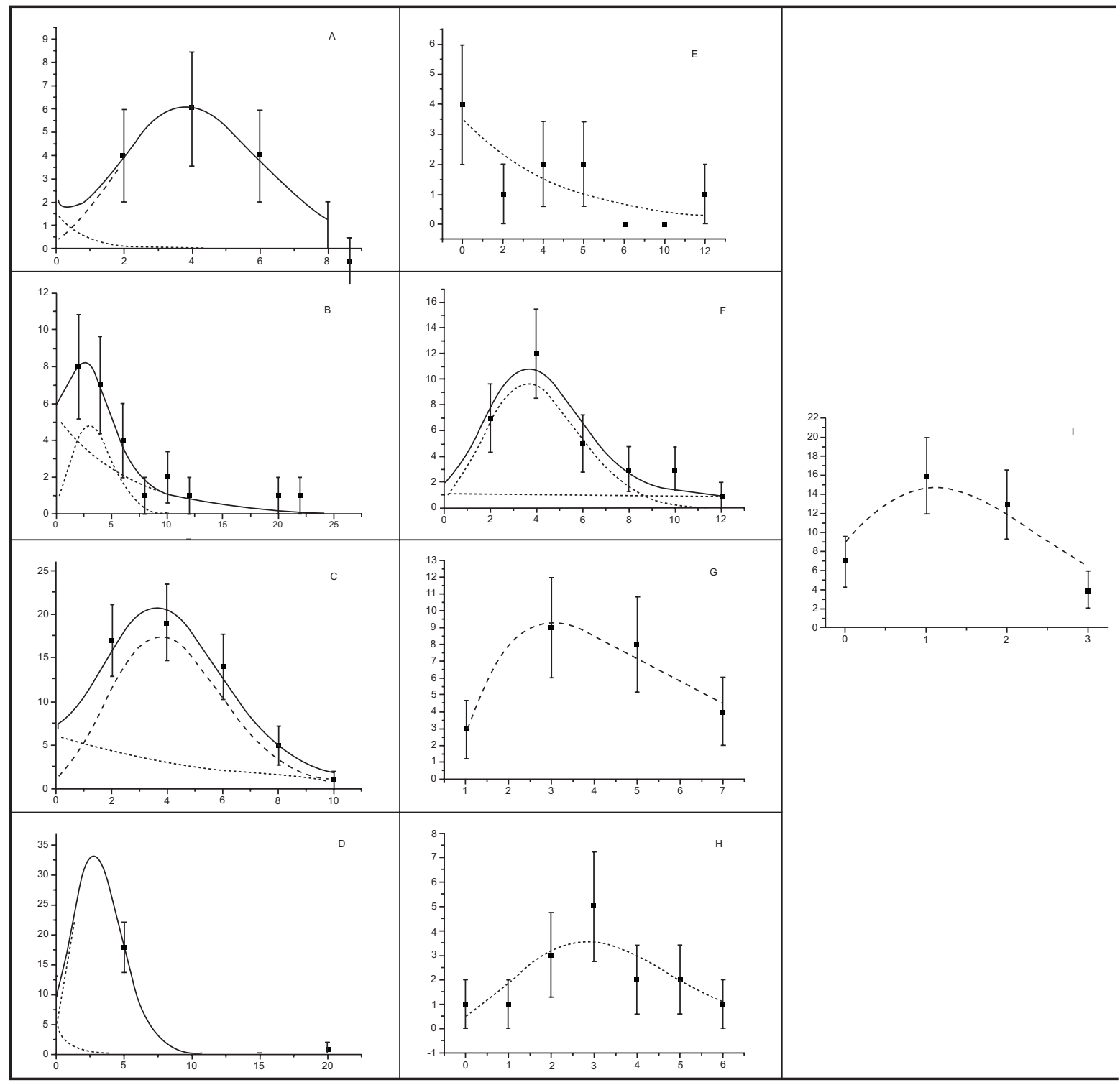

Fig. (5). Statistical modeling of distributions of persons of different generations on the frequency of cells with CAs occurrence. X-axis - frequency of cells with CAs, \%; Y-axis - frequency of occurrence, \%. Sample persons living in settl. Samburg (A-D); settl. M. Goloustnoe (E$\mathbf{H})$; c. Novosibirsk (I). Parents (A, E); children $(\mathbf{B}, \mathbf{F})$; grandchildren $(\mathbf{C}, \mathbf{G})$; great-grandchildren $(\mathbf{D}, \mathbf{H})$. Total curve of approximation ( $($ ); Poisson component (ーーー); Geometrical one (- - ). Standard errors of total approximation curve are shown.

trol value (1.4) (Table 4). This tendency may reflect the deaths of individuals with small numbers of lymphocytes (these persons are "G-distributed" [43]) and more resistant young individuals than old ones.

Bystander processes in resistant groups of persons lead to an increasing frequency of lymphocytes with CAs in blood samples, and the risk of these effects can be evaluated by $\mathrm{P}$ parameters. The frequency of lymphocytes with CAs is $3.2 \pm$ 0.3 for $50 \%$ of persons less than 18 years old, whereas it is $5 \%$ in the control group (Table 4). Selection (death of sensitive persons) is connected with lymphocyte depletion: persons with lymphocyte deficiencies are those with blood diseases, which were accounted in the presented statistics. They form a "group of risk" which can be determined by G value. The $P$ and $G$ values demonstrate that the processes of genome instability and selection prevail in the oldest generation.
A comparison of genome instabilities of persons living in the Tyumen and Irkutsk regions shows that the sample means of $\mathrm{P}$ distributions for both regions are approximately equal. Distributions of parents' and children's samples from settlements M. Goloustnoe and grandchildren's sample from settlements Samburg reveal a G component. Taking into account the absence of lymphocyte activation in many of the Samburg individuals, we can surmise that stronger and continued radiation effects are caused by the food chain of the North nations" "lichen-reindeer-man".

\section{DISCUSSION AND CONCLUSIONS}

\section{Statistical Model of Adaptation}

Genetic instability has long been considered as material for evolution [10, 44, 45]. Appearance of multiple mutations in blood lymphocytes of workers in radiochemical enterprises was analyzed by Bochkov and Chebotarev $[15,16]$, 
Table 4. Frequency of CAs in Blood Lymphocytes of Persons Living in Tyumen and Irkutsk Regions, and Novosibirsk City, Parameters of Most Effective Model of Approximation

\begin{tabular}{|c|c|c|c|c|c|c|c|c|c|c|c|c|c|c|}
\hline \multicolumn{15}{|c|}{ Settlements Samburg, Tyumen region } \\
\hline Age & No & N1 & $\mathbf{0}$ & 2 & 4 & 6 & 8 & 10 & 12 & 14 & 16 & $>18$ & $\mathbf{m G / G}$ & $\mathbf{m P} / \mathbf{P}$ \\
\hline $50-80$ & 24 & 7 & 2 & 4 & 6 & 4 & 1 & 0 & 0 & 0 & 0 & 0 & $0.2 / 1.7$ & 4.2/15.4 \\
\hline $39-49$ & 36 & 4 & 6 & 8 & 7 & 4 & 1 & 2 & 1 & 0 & 0 & 2 & $5.0 / 19.3$ & 3.5/11.1 \\
\hline \multirow[t]{2}{*}{ Age } & \multirow[t]{2}{*}{ No } & \multirow[t]{2}{*}{ N1 } & \multicolumn{10}{|c|}{ Frequency } & \multicolumn{2}{|c|}{$\mathbf{G}, \mathbf{P}$} \\
\hline & & & 0 & 5 & 10 & 15 & 20 & 0 & 0 & 0 & 0 & 0 & mG/G & $\mathrm{mP} / \mathrm{P}$ \\
\hline$<18$ & 29 & - & 10 & 18 & 0 & 0 & 1 & 0 & 0 & 0 & 0 & 0 & - & $3.3 / 28.1$ \\
\hline \multicolumn{15}{|c|}{ Settlements Maloe Goloustnoe, Irkutsk region } \\
\hline $60-80$ & 10 & 3 & 4 & 1 & 2 & 2 & 0 & 0 & 1 & 0 & 0 & 0 & $3.0 / 9.9$ & - \\
\hline $40-60$ & 32 & 4 & 1 & 7 & 12 & 5 & 3 & 3 & 1 & 0 & 0 & 0 & $5.8 / 7.3$ & 4.2/24.6 \\
\hline \multirow[t]{2}{*}{ Age } & \multirow[t]{2}{*}{ No } & \multirow[t]{2}{*}{$\mathbf{N 2}$} & \multicolumn{10}{|c|}{ Frequency } & \multicolumn{2}{|c|}{$\mathbf{G}, \mathbf{P}$} \\
\hline & & & 0 & 1 & 2 & 3 & 4 & 5 & 6 & 7 & 8 & 9 & mG/G & $\mathbf{m P} / \mathbf{P}$ \\
\hline $18-40$ & 23 & 1 & 1 & 1 & 3 & 6 & 4 & 4 & 3 & 1 & 0 & 0 & - & $4.0 / 23.7$ \\
\hline$<18$ & 15 & - & 1 & 1 & 3 & 5 & 2 & 2 & 1 & 0 & 0 & 0 & - & 3.1/15.3 \\
\hline \multicolumn{15}{|c|}{ Novosibirsk } \\
\hline
\end{tabular}

Standard error of sample means $\mathrm{d}(\mathrm{mP})=10-15 \%, \mathrm{~d}(\mathrm{mG})=30-40 \%$. The control group consisted of persons from Novosibirsk, the number of analyzed lymphocytes exceeding 100 in each blood sample. N0, total number of examined persons; N1, number of persons in whose blood samples the lymphocytes were not activated; N2, number of persons in whose blood samples the number of activated lymphocytes did not exceed 30; N3, the number of persons in whose blood samples the number of analyzed lymphocytes exceeded 100.

who first used statistical modeling. This statistical approach was developed by Arutyunian et al. who showed that $\mathrm{G}$ and $\mathrm{P}$ distributions in the case of multiple CAs in blood lymphocytes of patients with a syndrome of chromosomal instability [17]. These three authors suggested an idea based on queues theory [15] of connection tail of distributions with DNA repair. On the other hand, the investigations and modeling of fitness distributions were provided by Fisher [46], Gillespie [47], and Orr [18]. Orr showed the universal character of distributions with tails in evolutionary models and the connection of this phenomenon with selection [18]. In Russia, Korogodin and his colleagues provided a series of investigations in the 1970s which showed the connection of instability with summarized chromosomal aberrations [10] induced by low dose irradiation or non-optimal conditions [48]. Our model of adaptation is founded on the time-dependent accumulation of abnormalities and time-dependent selection based on repair filtering [19, 21]. Its parameters indicate selection (relative value of distributions) and intensity of damaging processes (sample mean of distribution).

\section{Influence of Irradiation Dose Rate on Instability and Selection}

Investigations on pea seeds showed that the parameters of the $\mathrm{G}_{\mathrm{s}}$ and $\mathrm{G} 2_{\mathrm{c}}$ distributions change at $0.3-1.2 \mathrm{cGy} / \mathrm{h}$ in comparison with the control group: the sample mean increases and the relative value decreases. The $\mathrm{P}$ component is displayed at the higher dose rate $(19.1 \mathrm{cGy} / \mathrm{h})$ whose sample mean was low (Table 3). We can observe increased late processes with low-dose-rate irradiation, which are displaced by intensive primary damage to cells and DNA. Investigations on plantain seeds showed that the parameters $\mathrm{mG}_{\mathrm{s}}$, both $\mathrm{mG} 2_{\mathrm{c}}, \mathrm{mP}_{\mathrm{c}}$ increase with radiation intensity and then fall back (Fig. 3C, Fig. 4C; curve 2). This fall of the sample mean is coupled with a dramatic diminution of the relative values of $G_{s}$, both $G 2_{c}$, and $P_{c}$ at high-dose-rate irradiation (Fig. 3D, Fig. 4D; curve 2). Thus, the intensities of both late processes and selection depend on the irradiation dose rate. Intensive primary damage becomes dominants under late process in the $\mathrm{G} 2_{\mathrm{c}}$ subpopulation when $\mathrm{I}_{\mathrm{rad}}>\mathrm{I}_{\mathrm{reg}}$. 
Table 5. Statistical Modeling on Blood Lymphocytes of People who Lived in t. Seversk and Workers in its Radiochemical Industry

\begin{tabular}{|c|c|c|c|c|c|c|c|}
\hline Group & Modeling & G1 & mG1 & G2 & mG2 & $\mathbf{P}$ & $\mathbf{m P}$ \\
\hline Workers, $0.93 \div 1.57 \mathrm{~Sv}$ & $\mathbf{G 1 + P}$ & 0.03 & 1.49 & - & - & 0.97 & 0.04 \\
\hline
\end{tabular}

Standard errors of parameters did not exceed $10-15 \%$. Data on chromosomal aberrations are published in [16]. The hypotheses "P" and "G" do not satisfy the criterion $\chi^{2}$ ( $\mathrm{p}>0.05$ ).

A similar conclusion results from the statistical modeling of CAs in blood lymphocytes of inhabitants and workers of radiochemical enterprises based on data published in [16] (Table 5). For the "inhabitants" and "workers irradiated with $0.18 \div 0.37 \mathrm{~Sv}^{\prime}$ the risks of chromosomal instability in blood lymphocytes are $4 \%$ and $7 \%$, respectively; the averaged number of CAs per cell is about 1 . We can conclude that radiation effects are equal for these two groups of persons because the characteristics of the resistant as well as the sensitive groups are almost identical. For the third group of persons, $97 \%$ of cells have primary damages with an averaged number per cell of about 0.04 .

\section{Dependence of Relative Values of $P$ and G Distributions on Antioxidant Status}

For plantain seeds collected in different populations of neighboring ecosystems (relative NPP fallout dose rate $=82$ r.u), the parameters of the $P_{s}$ and $G_{s}$ distributions (Fig. 3B, curves 1,2 ) and the $\mathrm{G} 2$ c distribution (Fig. $4 \mathbf{B}$, curve 2) differed $(\mathrm{p}<0.05)$ depending on the seeds' antioxidant status. This suggests that antioxidants influence selection connected with radioprotection in plants; this conclusion agrees with investigations published in [49].

\section{Dependence of Sample Mean of Distributions on Anti- oxidant Status}

Dependence is observed of the intensity of the bystander process $\left(\mathrm{mG}_{\mathrm{s}}\right.$, Fig. 3A, curve 2$)$ on antioxidant status ( $<$ 0.05 ). This result agrees with investigations which showed the involvement of energy metabolism in the production of bystander effects by radiation [50]. No influence of antioxidant status on the sample means $\mathrm{mG}_{\mathrm{c}}, \mathrm{mG}_{\mathrm{c}}$ and $\mathrm{mP}_{\mathrm{c}}$ was revealed in these plantain studies (Fig. 4A), perhaps because sample sizes were not sufficient. The hypothesis has been made that the phenomenon of hypersensitivity can be a result of oxidative stress [51]. The authors of this paper investigated effects of low-dose radiation on human blood lymphocytes over a range from 1 to $50-70 \mathrm{cGy}$, which is higher than around the NPP. In our calculations, each seedling's meristem experiences an influence of even one g-quantum per 3 months in the 20-km NPP zone [21]. We suppose that multiple DNA damages could appear due to affected mass cellular structures. This conclusion agrees with the opinion of Mothersill and Seymour concerning the role of epigenetic factors in low-dose effects [52].

\section{Continued Adaptation Across Generations}

The induction of genome instability by low-dose irradiation is well documented [9]. The study of genetic instability across generations of mice irradiated with low-dose-rate radiation indicates a genetic instability in the F1, F2, and F3 generations from irradiated males [53]. Our analysis of the structure of distributions of samples from persons living in settl. Samburg and Maloe Goloustnoe on the number of CAs in blood lymphocytes shows instability which continues across three generations of irradiated individuals, because the $\mathrm{mP}$ values of distributions of youngsters' samples are increased (Table 4, Fig. 5). Model characteristics indicate the significance of resistance in individuals (youngsters' samples) which plays the main role in selection in blood lymphocytes: samples of older individuals are characterized by a $\mathrm{G}$ distribution on the number of lymphocytes with CAs (Fig. 5) and on lymphocyte depletion (Table 4). Finally, it was revealed that the intensity of bystander processes and selection are higher in settlement Samburg, and this can be connected with a stronger radiation influence due to the food chain of "lichen-reindeer-man". All these prevail upon the phenomenon of chromosomal instability and should be considered as components of the adaptive process.

\section{Calculation of Risks of Instability in Ecology and Epide- miology}

The risk of bystander effects in tissues, coupled or not by selection processes, can be calculated by means of the parameters of $\mathrm{G}$ and $\mathrm{P}$ distributions. The risks of chromosomal instability can be determined by values of the $\mathrm{G}$ distribution of cells on the CAs number. A P distribution with a low $\mathrm{mP}$ value indicates primary abnormalities, but an increasing $\mathrm{mP}$ value indicates a diminution of late processes [19].

\section{CONCLUSIONS}

- A statistical model of adaptation is founded on the concepts of time-dependent accumulation of abnormalities and time-dependent selection based on repair filtering. Effects of low-dose-rate irradiation in tissues and cells of plant seedlings and individuals were described by means of the model of adaptation. Its parameters indicate intensity of damaging processes (sample mean of distribution) and selection (relative value of distributions).

- Low-dose-rate irradiation increases sample means and decreases relative values of $\mathrm{G}$ distributions, signs of late damage processes and selection. Relative values of $\mathrm{P}$ and $\mathrm{G}$ distributions increased concomitantly with antioxidant status, indicative of an inverse relation between selection and antioxidant status. Investigations on plantain seeds showed an influence of antioxidant status on sample means of P and G distributions of seedlings on the number of cells with abnormalities, suggesting an involvement of oxidants in bystander mechanisms. 
- $\quad$ Synergism of irradiation and heat stresses is a result of late damage processes which lead to decreasing numbers of CAs and cells with CAs $\left(\mathrm{K}_{\mathrm{syn}}<1\right)$ and thence to the death of seedlings $\left(\mathrm{K}_{\mathrm{syn}}=4\right)$.

- In old seeds, the statistical modeling revealed P distributions on the number of CAs characterized by low sample means in control seeds and seeds irradiated at $19.1 \mathrm{cGy} / \mathrm{h}$. This result suggests that these P distributions are formed by cells with primary damages that involving strong mutagenic effects of aging and irradiation at $19.1 \mathrm{cGy} / \mathrm{h}$.

- $\quad$ Statistical modeling on the basis of investigations of blood lymphocytes of samples of four generations of people living in settl. Samburg (Tyumen region) and settl. Maloe Goloustnoe (Irkutsk region) shows increasing sample means of $\mathrm{P}$ distributions of youngsters' samples of settl. Samburg and M. Goloustnoe over the control level. This result suggested a bystander processes in blood lymphocytes. Age, region and national traditions also play a part in radiationinduced adaptive processes in these sites.

- $\quad$ The model parameters can be used to calculate risks of adaptive and instability processes. Risk of bystander effects in tissues, coupled or not with selection processes, can be calculated by the parameters of $\mathrm{G}$ and $\mathrm{P}$ distributions. Risks of chromosomal instability can be estimated by values of the $G$ distribution of cells on CAs numbers. A P distribution with a low $\mathrm{mP}$ value indicates primary abnormalities, but an increasing $\mathrm{mP}$ value means diminution of late processes.

\section{ACKNOWLEDGEMENTS}

The authors would like to express their gratitude to V.B. Priezzhev and G.A. Ososkov for their consultations on the mathematics and statistics; to G.A. Debelyi for kindly providing the initial pea seeds; to Yu.A. Kutlakhmedov for helpful discussions; to R.M. Aroutyunian for comments on the manuscript; to N.A. Sen'kova for cytogenetic studies of blood lymphocytes of persons living in Siberia; to A.B. Florko for technical consultations. The authors are grateful to J. Drake for his regards and consideration of our investigations of mutation processes and evolution.

\section{REFERENCES}

[1] Ilyina, V.L.; Korogodin, V.I.; Fajszi, Cz. Dependence of spontaneous reversion frequencies in haploid yeasts of different genotypes on the concentration of adenine in the medium and on the age of the culture. Mutat. Res., 1986, 174, 189-194.

[2] Cairns, J.; Overbaugh J.; Miller S. The origin of mutants. Nature, 1988, 335, 142-145.

[3] Foster, P. L. Adaptive mutation: the uses of adversity. Annu. Rev. Microbiol., 1993, 47, 467-504.

[4] Galhardo, R.S.; Hastings, P.J.; Rosenberg, S.M. Mutation as a stress response and the regulation of evolvability. Crit. Rev. Biochem. Mol. Biol., 2007, 42, 399-435.

[5] Mothersill, C.; Seymour, C.B. Genomic instability, bystander effect and radiation risks: implications for development of protection strategies for man and environment. Radiats. Biol. Radioecol., 2000, 40, 615-620.

[6] Mothersill, C.; Seymour, C.B. Radiation-induced bystander effects: past history and future directions. Radiat. Res., 2001, 55, 759-767.

[7] Lorimore, S.A.; Wright, E.G. Radiation-induced genomic instability and bystander effects: related inflammatory-type responses to radiation-induced stress and injury? Int. J. Radiat. Biol., 2003, 79, $15-25$.

[8] Morgan, W.F. Non-targeted and delayed effects of exposure to ionizing radiation: II. Radiation-induced genomic instability and bystander effects in vivo, clastogenic factors and transgenerational effects. Radiat. Res., 2003, 159, 581-596.

[9] Mothersill, C.; Seymour, C.B. Radiation-induced bystander effects and the DNA paradigm: an "out of field" perspective. Mutat. Res. 2006, 597(1-2), 5-10.

[10] Korogodin, V. I.; Bliznik, K. M.; Kapultsevich, Yu. G. Regularities of radiorace formation in yeasts. Comm. 11. Facts and hypotheses. Radiobiologiya, 1977, 17, 492-499 (Russian).

[11] Rosenberg, S.M.; Thulin, C.; Harris, R.S. Transient and heritable mutators in adaptive evolution in the lab and in nature. Genetics, 1998, 148, 1559-1566.

[12] Rosenberg, S.M; Hastings, P.J. Adaptive point mutation and adaptive amplification pathways in the Escherichia coli Lac system: stress responses producing genetic change. J. Bacteriol., 2004, 186, 4838-4843.

[13] Wright, B.E. Stress-directed adaptive mutations and evolution. Mol. Microbiol., 2004, 52, 643-650.

[14] Korogodina, V.; Bamblevsky, V.; Grishina, I.; Gustova, M.; Florko, B.; Javadova, V.; Korogodin, V.; Lozovskaya, E.; Malikov, A.; Maslov, O.; Melnikova, L.; Shlyakhtin, G.; Stepanchuk, V.; Zueva, M. Evaluation of the consequences of an influence of stress factors on seeds of plant growing in a $30-\mathrm{km}$ zone of Balakovo NPP. Radiats. Biol. Radioecol., 2004, 44, 83-90 (Russian).

[15] Bochkov, N.P.; Yakovenko, K.N.; Chebotarev, A.N.; Funes Kravioto, F.; Zhurkov, V.S. Distribution of the damaged chromosomes on human cells under chemical mutagens effects in vitro and in vivo. Genetika, 1972, 8, 160-167 (Russian).

[16] Chebotarev, A.N. A mathematical model of origin multi-aberrant cell during spontaneous mutagenesis. Dokl. Biol. Sci., 2000, 371, 207-209 (Russian).

[17] Arutyunyuan, R.; Neubauer, S.; Martus, P.; Durk, T.; Stumm, M.; Gebhart, E. Intercellular distribution of aberrations detected by means of chromosome painting in cells of patients with cancer prone chromosome instability syndromes. Exper. Oncol., 2001, 23, 23-28 (Russian).

[18] Orr, H.A. The distribution of fitness effects among beneficial mutations in Fisher's geometric model of adaptation. J. Theor. Biol., 2006, 238, 279-285.

[19] Florko, B.V.; Korogodina, V.L. Analysis of the distribution structure as exemplified by one cytogenetic problem. Phys. Particles Nucl. Lett., 2007, 4, 331-338.

[20] Korogodina, V.L.; Bamblevsky, V.P.; Florko, B.V.; Korogodin, V.I. Variability and viability of seed plant populations around the nuclear power plant. In Impact of radiation risk estimates in normal and emergency situations; Cigna, A.A.; Durante, M.; Eds.; Springer: Netherlands, 2006; pp. 85-93.

[21] Korogodina, V.L.; Florko, B.V. Evolution processes in populations of plantain, growing around the radiation sources: changes in plant genotypes resulting from bystander effects and chromosomal instability. In A Challenge for the Future; Mothersill, C.; Seymour, C.; Mosse, I.B.; Eds.; Springer: Netherlands, 2007; pp. 155-170.

[22] Preobrazhenskaya, E. Radioresistance of Plant Seeds, Atomizdat: M., 1971 (Russian).

[23] Korogodina, V.L.; Panteleeva, A.; Ganicheva, I.; Lazareva, G.; Melnikova, L; Korogodin, V. Influence of the low gammairradiation dose rate on mitosis and adaptive response in meristem cells of pea seedlings. Radiats. Biol. Radioecol., 1998, 38, 643-649 (Russian).

[24] Korogodina, V.L.; Florko, B.V.; Korogodin, V.I. Variability of seed plant populations under oxidizing radiation and heat stresses in laboratory experiments. IEEE Trans. Nucl. Sci. 2005, 52, 10761083.

[25] Van der Vaerden, B.L. Mathematische statistik. Springer-Verlag: Berlin-Göttingen-Heidelberg, 1957.

[26] Pytjev, Yu.P.; Shishmarev, I.A. The course of probability theory and mathematical statistics for physicists. Moscow State University Press: M., 1983 (Russian).

[27] Geraskin, S.A.; Sarapultsev, B.I. Automatical classification of biological objects by the radiation stability level. Autom. Telemech., 1993, 2, 183 (Russian).

[28] Akaike, H. A new look at the statistical model identification. IEEE Trans. Autom. Control., 1974, AC-19, 716-723. 
[29] Schwarz, G. Estimating the dimension of a model. Ann. Stat., 1978, 6, 461-464.

[30] Rakhlin, A.; Panchenko, D.; Mukherjee, S. Risk Bounds for Mixture Density Estimation. ESAIM, 2005, 9, 220.

[31] CERN Program Library [http://www.jinr.ru/programs/cernovr. htm]

[32] Turchak, L. I. The Base of Numerical Methods. Nauka: M., 1987 (Russian).

[33] Kirkpatrick, S., Gelatt, C.D. Jr, Vecchi, M.P. Optimization by Simulated Annealing. Science, 1983, 220, 671-680.

[34] Wikipedia [http://en.wikipedia.org/wiki/BFGS_method].

[35] Feller, W. An introduction to probability theory and its applications, $2^{\text {nd }}$ ed.. John Wiley \& Sons: New York, Chapman \& Hall, Limited: London, 1957, vol. 1.

[36] Rainwater, D.T.; Gossett, D.R.; Millhollon, E.P.; Hanna, H.Y.; Banks, S.W.; Lucas, M.C. The relationship between yield and the antioxidant defense system in tomatoes grown under heat stress. Free Radic. Res., 1996, 25, 421-435.

[37] Pinzino, C.; Capocchi, A.; Galleschi, L.; Saviozzi, F.; Nanni, B.; Zandomeneghi, M. Aging, free radicals, and antioxidants in wheat seeds. J. Agric. Food Chem., 1999, 47, 1333-1339.

[38] Petin, V.G.; Zhurakovskaya, G.P.; Pantyukina, A.G.; Rassokhina, A.V. Low doses and problems of synergistic interaction of environmental factors. Radiats. Biol. Radioecol., 1999, 39, 113-126 (Russian).

[39] Korogodina, V.; Bamblevskij, V.; Grishina, I.; Gustova, M.; Zabaluev, S.; Korogodin, V.; Kuraeva, T.; Lozovskaja, E.; Maslov, O. Antioxidant status of plant (Plantago major L.) seeds of the populations growing in the Balakovo NPP and chemical enterprisers region, Radiats. Biol. Radioecol., 2000, 40, 334-338 (Russian).

[40] Osipova, L.P.; Koutsenogii, K.P.; Shcherbov, B.L.; Strakhovenko, V.D.; Petrov, S.A. Environmental Radioactivity for Risk Assessment of Health Status in Nature and Human Population of Northern Siberia In Proceedings of the 5-th International conference on environmental radioactivity in the Arctic and Antarctic: 16-20 June 2002; St. Petersburg, 2002; pp. 124-127 (Russian).

[41] Medvedev, V.I.; Korshunov, L.G., Chernyago, B.P. Radiation effect of Semipalatinsk' nuclear testing area on South Siberia (Long-term investigations on Eastern and Middle Siberia and their comparison with material on Western Siberia) Siberia' Ecol. J., 2005, 12, 1055-1071.

[42] Osipova, L.P.; Ponomareva, A.V.; Shcherbov, B.L.; Sukhorukov, F.; Strakhovenko, V.; Kutsenogij, K. Aftermath of radiation effect in population of tundra Nenets inhabitants, Purov region, YaNAD
In Proceedings of the First International Conference dedicated to the Centenary of the Birth of N.W.Timofeeff-Ressovsky: 7-9 September 2000; Korogodin, V.I.; Korogodina, V.L.; Dubrovina, N.I.; Eds.; JINR Press: Dubna, 2001, pp. 200-212 (Russian).

[43] Antonova, E.; Osipova, L.P.; Florko, B.V., Korogodina, V.L. The comparison of distributions of individuals with normal and bad stimulated blood cells' activity on the frequency of aberrant cells' occurrence in blood lymphocytes. Rep. Russ. Mil-Med. Acad., 2008, Application 1, 3: 73 (Russian).

[44] Herman, R.K.; Dworkin, N.B. Effect of gene induction on the rate of mutagenesis by ICR-191 in Escherichia coli. J. Bacteriol., 1971, $106,543-50$.

[45] Rosenberg, S. M. Mutation for survival. Curr. Opin Genetics. Dev., 1997, 7, 829-834.

[46] Fisher, R.A. The Genetical theory of natural selection. Oxford University Press: Oxford, 1930.

[47] Gillespie, J. H. A simple stochastic gene substitution model. Theor. Popul. Biol., 1983, 23, 202-215.

[48] Bliznik, K. M.; Kapultsevich, Yu. G.; Korogodin, V. I.; Petin, V. G. Formation of radioraces by yeasts. Comm.4. The dependence of saltant yield on postirradiation cultivation conditions. Radiobiology, 1974, 14, 229-236 (Russian).

[49] Zhuravskaia, A.N.; Filippov, E.V.; Kershengol'ts, B.M. The effect of the biochemical adaptations in the Manchu alder (Duschecia fruticosa (Rupr)) to an elevated natural radiation background on the survivability of seedlings and on the radiosensitivity of its seeds. Radiats. Biol. Radioecol., 2000, 40, 254-260 (Russian).

[50] Mothersill, C.; Stamato, T.D.; Perez, M.L.; Cummins, R.; Mooney, R.; Seymour, C.B. Involvement of energy metabolism in the production of 'bystander effects' by radiation. Br. J. Cancer. 2000, 82, 1740-1746.

[51] Nasonova, E.A.; Shmakova, N.L.; Komova, O.V.; Mel'nikova, L.A.; Fadeeva, T.A.; Krasavin, E.A. Cytogenetic effects of low dose radiation with different LET in human peripheral blood lymphocytes and possible mechanisms of their realization. Radiats. Biol. Radioecol., 2006, 46, 457-460 (Russian).

[52] Mothersill, C.; Seymour, C. Radiation-induced bystander effects, carcinogenesis and models. Oncogene, 2003, 22, 7028-7033.

[53] Zaichkina, S.I.; Rozanova, O.M.; Akhmadieva, A.Kh,; Aptikaeva, G.F.; Sorokina, S.S.; Smirnova, E.N.; Romanchenko, S.P.; Vakhrusheva, O.A. Study of the genetic instability in generations of mice irradiated of a low-dose rate of high-LET radiation. Radiats Biol. Radioecol., 2009, 49, 55-59 (Russian)

(C) Korogodina et al.; Licensee Bentham Open.

This is an open access article licensed under the terms of the Creative Commons Attribution Non-Commercial License (http://creativecommons.org/licenses/by-nc/3.0/) which permits unrestricted, non-commercial use, distribution and reproduction in any medium, provided the work is properly cited. 